\title{
Performance analysis of berth configurations at container terminals
}

\author{
Iris F. A. Vis - Roel G. van Anholt
}

Published online: 9 March 2010

(C) The Author(s) 2010. This article is published with open access at Springerlink.com

\begin{abstract}
The containerized trade market has been growing rapidly since its introduction. The capacity of ships and the amount of containers being transshipped at container terminals increases significantly. Terminals should handle their operations efficiently to provide the necessary capacity and customer service. In designing a container terminal, terminal management has to consider the choice for a certain type of berth. In this paper, we compare by means of a simulation study the performance of traditional one-sided marginal berths and indented berths. An indented berth enables quay cranes to unload and load containers from both sides of the ship. As a result, more quay cranes can work on a single ship. As main performance measure in this comparison we use the total vessel operation time required to unload and load a ship. This time depends next to crane productivity also on the efficiency of the transportation and storage and retrieval processes in the terminal. We have performed a sensitivity analysis in which we also study the relation between the selection of an indented berth and other design and control issues in the terminal.
\end{abstract}

Keywords Container terminals · Indented berth · Performance analysis . Design · Simulation

\footnotetext{
I. F. A. Vis $(\varangle) \cdot$ R. G. van Anholt

Department of Information Systems and Logistics, Faculty of Economics and Business Administration, VU University Amsterdam, De Boelelaan 1105, 1081 HV Amsterdam, The Netherlands e-mail: ivis@feweb.vu.nl

R. G. van Anholt e-mail: ranholt@feweb.vu.nl
} 


\section{Introduction}

Since the 1950s, more and more cargo is being containerized and export and import is increasing on a global scale. The high growth rate of containerized trade is more recently initiated by the uprising of the Far East. The capacity of ships has been extended up to 12,000 twenty feet equivalent unit container (TEU) to ensure that all containers can be transported worldwide from port to port. Ports should be responsive and on guard to handle and to transship these massive volumes of containers. Docking times of ships should be as short as possible to satisfy carriers and the shippers of containerized goods. In other words, all terminal processes should be performed as efficiently as possible.

These processes are illustrated in Fig. 1 and can be described as follows. An arriving ship will moor at a berth. Quay cranes are positioned on the quays at the berth. These cranes unload containers according to an unload plan. Next, these containers need to be transported to the storage area (i.e., stack). Different types of transport systems can be used. When a terminal uses vehicles without lifting capabilities (e.g., automated guided vehicles), a vehicle needs to be available to receive the container the moment the container has been taken out off the ship's hold or deck. In that way delays in the unloading process can be limited. Consequently, the (un-)loading and transportation processes depend on each other. Self-lifting vehicles (e.g., straddle carriers) are able to lift a container from the ground. When such a type of vehicle is deployed, quay cranes will position retrieved containers at a marshalling area at the quay. Here, the (un-)loading and transportation processes are decoupled. A marshalling area usually has a finite capacity which depends on the available space at the quay. A self-lifting vehicle needs to lift a container before this area is completely full. In that way, a quay crane can continue its operation without any delays.

The transport vehicles transship the containers to the stack to be stored. A stack consists of multiple blocks of containers. Each block of containers has multiple parallel rows, each with a fixed number of storage locations. Containers will be stored temporarily upon further transportation to their (final) destinations by other modes of transportation. Different types of storage equipment can be used to store and retrieve containers from the stack. (Automated) yard cranes span multiple rows of containers. They receive containers from the transport vehicles and store them into the stack. If self-lifting vehicles execute the transportation process, it can be decided to have them store the containers in the stack by themselves. All processes can be executed in a reverse order to load containers on a ship. A load plan indicates the order in which containers should be loaded on the ship.

Terminal management needs to address multiple decision problems to design an efficient container terminal. Vis and De Koster (2003), Steenken et al. (2004) and more recently Stahlbock and Voss (2008) provide an overview of all relevant decision problems and related literature. As described in Vis and De Koster (2003), three planning and control levels can be distinguished in this design process. At the strategic level, long-term decisions are taken which are mainly related to the terminal layout and selection of the transport and storage systems to be used. The selection of the transport and storage systems directly influences the way all logistics processes will be performed as explained in Fig. 1. Vis (2006) compares different types of storage 


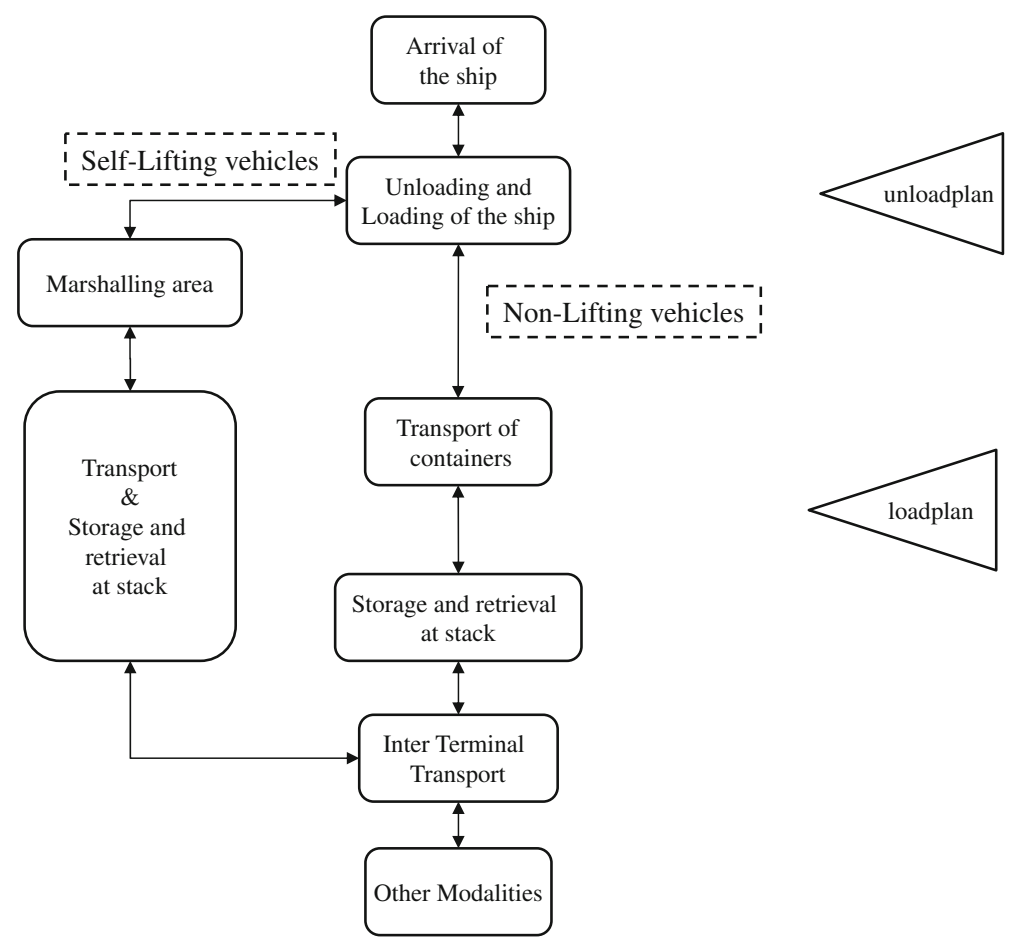

Fig. 1 Processes at a container terminal

systems by means of a simulation study. Vis and Harika (2004) compare different types of transport systems by performing a simulation study in which they model a terminal with lifting and non-lifting vehicles. Typical layout issues concern the selection of the type of berth used, the locations of the stacks, and the specific layout of each of the individual areas. For example, Kim et al. (2007) compare various ways of positioning stacks to the berth, namely parallel and perpendicular positioning. We will focus in this paper on the strategic problem of selecting the type of berth configuration used in the terminal.

At the tactical level it has to be decided which planning and control policies for each of the logistics processes in the terminal will be implemented. For example, a policy needs to be selected to allocate ships to berths (e.g., Imai et al. 2001), to sequence storage and retrieval requests in the stack (e.g., Vis and Roodbergen 2009) or to dispatch containers to vehicles (e.g., Bish et al. 2001). At the operational level all detailed daily decisions need to be made. Decisions at one level directly influence decisions at another level. For example, the layout of the terminal directly influences the performance of all logistics processes and the productivity of the terminal. Therefore, it is advised to consider the decisions at the various levels in relation to each other. In this paper, we will study the berth design selection problem in relation to other design and control issues in the terminal. From the literature overviews, we can conclude that simulation has achieved a growing importance among researchers and terminal 


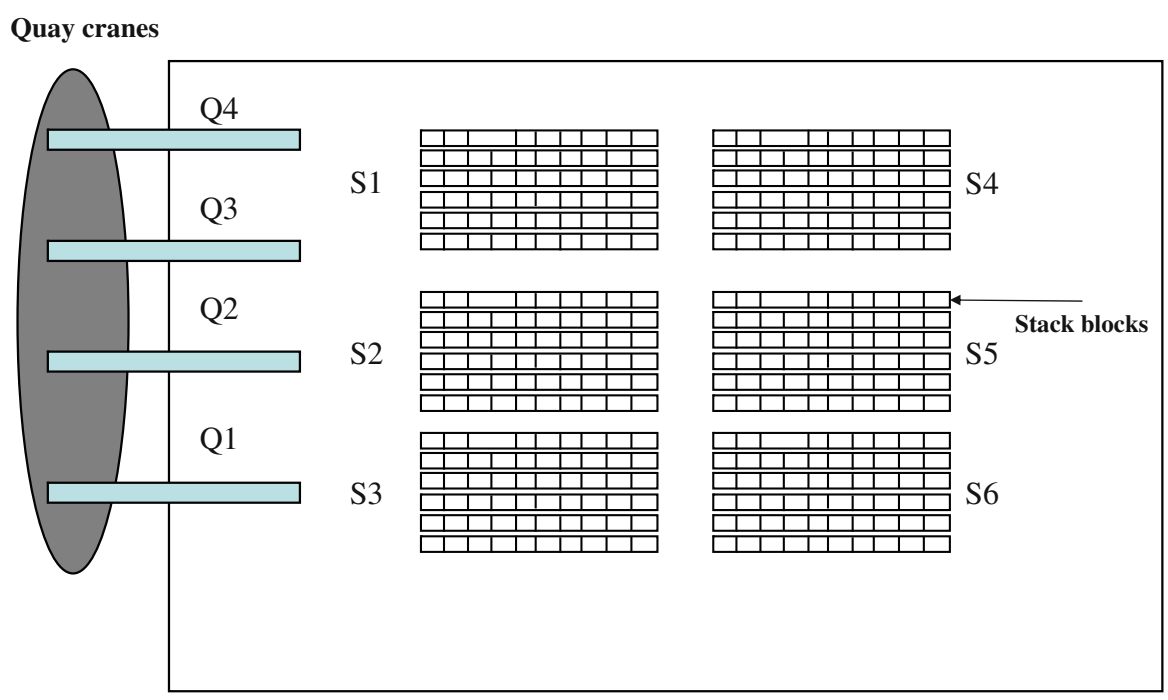

Fig. 2 Marginal berth with stacks (specific numbers will be introduced in Sect. 2)

operators to compare layout and system alternatives, to test optimization methods and to study the impact of one decision on another (Steenken et al. 2004).

The objective of this research is to study the strategic decision problem of selecting a type of berth for a container terminal. We perform a comparative analysis on various types of berth configurations by means of a simulation and study the impact on the logistics processes in the rest of the terminal. A traditional berth, also referred to as a marginal berth, consists of a single quay where ships can moor. An indented berth has quays at three sides of the ship. This type of berth enables quay cranes to unload and load ships at both sides of the ship and to stack containers around the ship. As a result, more quay cranes can work simultaneously on a single ship. If all other terminal processes are designed well (i.e., layout, amount of equipment and control policies) it might be expected that the terminal productivity will increase compared to a marginal berth. Possible designs for terminals with marginal and indented berths are, respectively, depicted in Figs. 2 and 3. Worldwide only the Amsterdam Container Terminals (formerly: Ceres Paragon Terminal) in Amsterdam, The Netherlands has an indented berth. Therefore, we use data obtained from this terminal in our research.

Imai et al. (2007) were among the first authors to study an indented berth. The authors study the berth allocation problem in indented berths. The model allows for multiple ships to moor at this type of berth at the same time. A direct consequence is that the inner most ship at the berth never can leave earlier than the outer most ships. Given this specific constraint and assumptions on different space requirements for each type of berth, the authors perform a simulation study to compare both types of berths. It is concluded that the total service time for serving multiple ships at the same time is higher with an indented berth due to waiting times. In their experiments, the authors assume that a large ship in an indented berth actually occupies cranes operating at two berths. As a result, fewer ships can be handled at the same time compared to marginal 


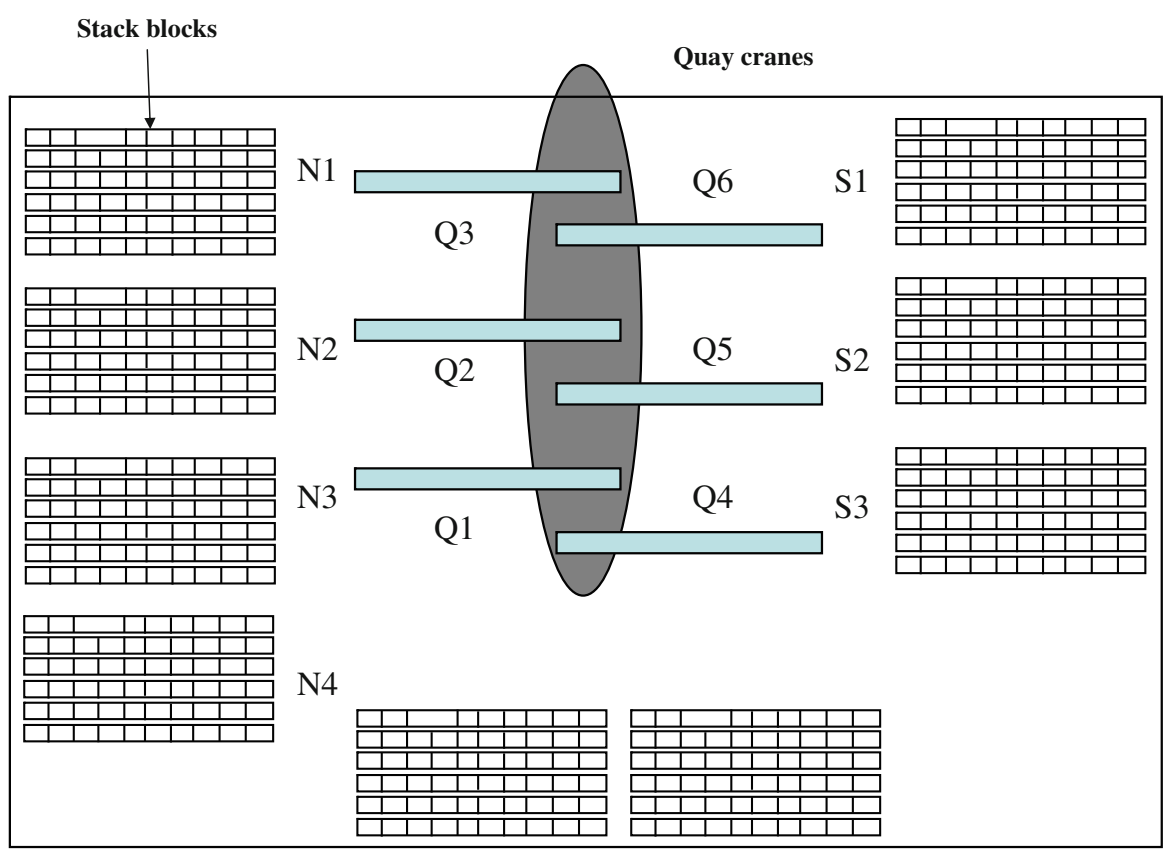

Fig. 3 Indented berth with stacks (specific numbers will be introduced in Sect. 2)

berths. We extend the research of Imai et al. (2007) in this paper, by performing a more exhaustive comparison with multiple simulation experiments.

Specifically, we consider two completely identical terminals except for specific berth configuration characteristics, such as the quay crane assignment. Furthermore, given the current increase in ship sizes and the design decisions made at the Amsterdam Container Terminals, we assume that an efficient terminal configuration consists either of multiple small indented berths each allowing a single ship to moor or a combination of an indented berth for a single ship and a marginal berth to handle multiple ships at the same time. This latter configuration is implemented at Amsterdam Container Terminals. Here, both ships with a small workload (i.e., number of containers to be handled) and a large workload are handled in the indented berth. Ships moor at the north side of the berth. As a result, the processing times of QCs at the south side will be somewhat longer due to the fact that the containers need to be transported over water. Some of the quay cranes positioned at the indented berth are flexible and can be assigned to both types of berths. As a result, ships do not have to wait for each other to leave after the unloading and loading processes have been finished. Therefore, we will consider, contrary to Imai et al. (2007), the vessel operation time for a single ship as the main performance measure. Contrary to many other papers addressing terminal processes (e.g., Vis and Harika 2004; Nguyen and Kim 2007) we study self-lifting vehicles that both perform the transportation and storage processes (refer to the left side of Fig. 1). In Sect. 2, we will provide a more detailed problem description. Furthermore, we will define a baseline scenario. Section 3 presents the specifications of 
the simulation model. Results for all experiments including the baseline scenario and a sensitivity analysis will be described in Sect. 4. Section 5 presents conclusions.

\section{Problem description}

We consider the following situation. Either the terminal has an indented berth or a marginal berth where a ship with a known workload can moor. Containers are being unloaded (import) and loaded (export) by Quay Cranes (QCs). The number of QCs assigned to a ship differs per type of berth and the number of containers to be handled. A marshalling area is available at each QC, where QCs can drop off import containers and to pick up delivered export containers. Straddle Carriers (SCs) perform both the transportation and the storage and retrieval process. The SCs travel along pre-defined paths between the stack and the ship. We consider both the unloading and loading process of a ship. As a result, we can use the total time required to handle a single ship as performance measure in our comparison.

As explained in Sect. 1, we will use operational data of Amsterdam Container Terminals in the Netherlands in our simulation study. This terminal covers 54 hectares of ground and has a total quay length (including both an indented and marginal berth) of $1050 \mathrm{~m}$. The annual capacity of the terminal is estimated to be 1,000,000 TEUs. At most 9 QCs can be scheduled to handle a ship at the indented berth. The indented berth has a length of $400 \mathrm{~m}$ and a width of $57 \mathrm{~m}$. The total time to moor at the quay of the indented berth (i.e., berth time) equals, according to estimates of Amsterdam Container Terminals, $15 \mathrm{~min}$. For more detailed information on this terminal and the port of Amsterdam, we refer to Kroon and Vis (2008).

In this study, we use data collected at the indented berth in the period June 2006May 2007. We consider a comparable configuration for a terminal with a marginal and a terminal with an indented berth to perform a fair comparison. We will only vary specific berth type characteristics such as the number of QCs.

Summarizing, the main assumptions in our model are:

- We study a single ship in one type of berth at the same time in our model. As a result, QCs that finish their jobs will not be assigned to a new set of tasks but will remain idle until the ship leaves the berth.

- At each QC a marshalling area with known storage capacity is available (see Sect. 2.1).

- The exact number of bays in a ship is known in advance (see Sect. 2.2).

- The exact number of import and export containers and their distribution over the various bays are known in advance (see Sect.2.2).

- A QC planning method is available to assign and schedule QCs in advance (see Sect. 2.3).

- The exact number of SCs in a pool assigned to each crane operating at a ship is known in advance (see Sect. 2.4)

- SCs are assigned to requests based on the heuristic rule "nearest-vehicle-first" (see Sect. 2.4).

- The storage capacity assigned to a ship is known in advance (see Sect.2.5) 


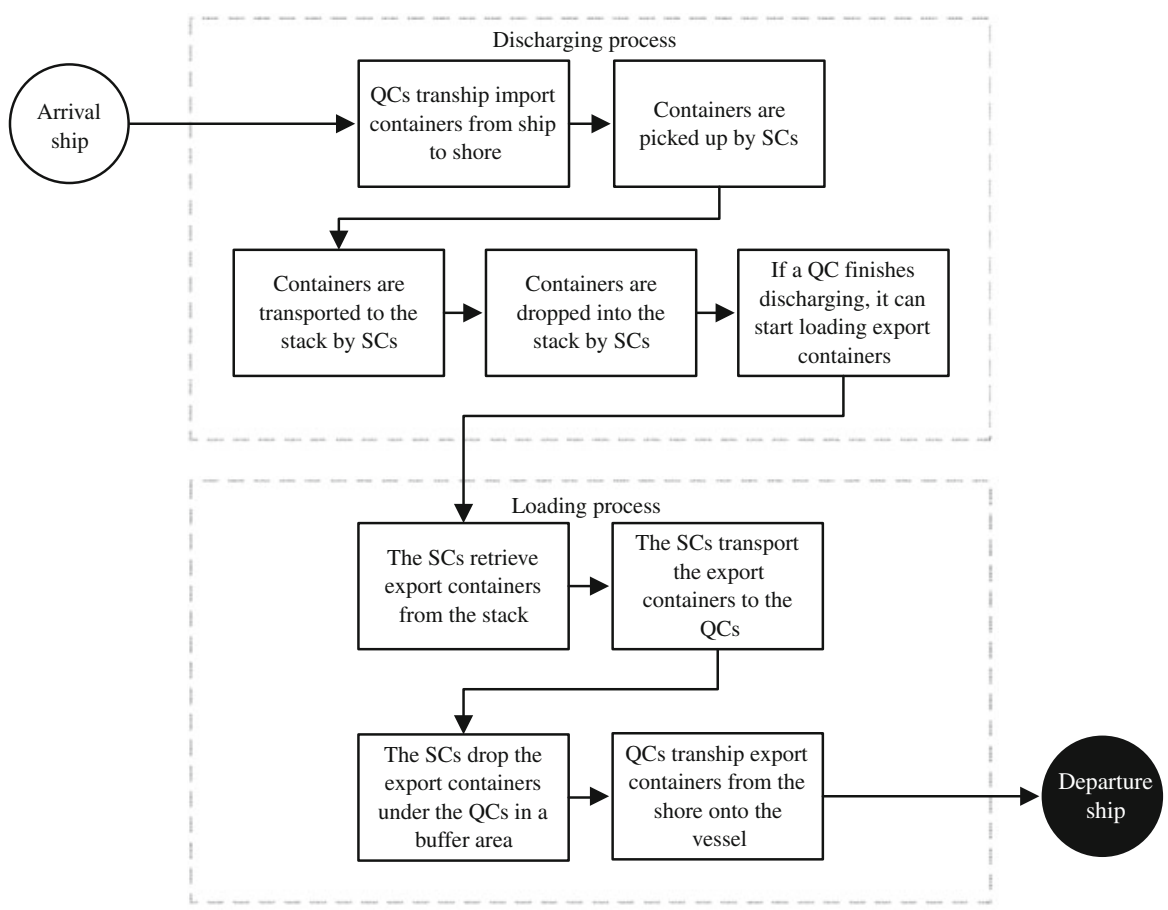

Fig. 4 Schematic overview of processes to handle a single ship which will be incorporated in the simulation model

Terminal configurations and relevant input data for each type of berth are known in advance and specified in the remainder of this section.

\subsection{Terminal configuration and processes}

Figure 4 provides a general overview of all terminal processes incorporated in the simulation study. The processes start with unloading (i.e., discharging) the ship and transporting the containers to the stack. When a QC finishes unloading, the loading process for that QC can start. As a result, it might occur that one QC is still unloading while the other one already started with the loading process.

SCs transport the containers to the ship. The model ends when the final container has been loaded on the ship. These processes match the general process description as provided in Sect. 1. The terminal layouts of a marginal and indented berth are represented in respectively Figs. 2 and 3. In the terminal, respectively, six and seven stack blocks with a similar total stack capacity (see Sect.2.5) has been assigned for the vessel operations. Namely, stack blocks N1-N4 at the north side of the berth and stack blocks S1-S3 at the south side of the berth are used for ships at the indented berth. The marginal berth uses six stack blocks S1-S6 at the south side of the berth. At each QC, a marshalling area is located to position containers. The capacity differs per side of the berth and equals either 2 (north side of indented berth) or 3 (south side of the indented 
Table 1 Workload at a ship and container characteristics

\begin{tabular}{lll}
\hline & $\begin{array}{l}\text { Ships with } \\
\text { a small workload }\end{array}$ & $\begin{array}{l}\text { Ships with } \\
\text { a large workload }\end{array}$ \\
\hline Number of bays & 15 & 17 \\
Number of moves & 881 & 2,050 \\
Import (\%) & 57.3 & 53.6 \\
$20 \mathrm{ft}$ import (\%) & 34.1 & 33.4 \\
$20 \mathrm{ft}$ export (\%) & 28.2 & 39.5 \\
\hline
\end{tabular}

berth and marginal berth). Numerous experiments with varying capacity demonstrate that vessel operation times are independent of the capacity at the marshalling area.

\subsection{Ship and container characteristics}

We examine two different types of ships, namely ships with a large workload (on average 2050 moves) and ships with a small workload (on average 881 moves). At Amsterdam Container Terminals, on average, more containers need to be unloaded than loaded. This is common for European ports that need to transship the increased flow of containers originating in Asia and more specific China (see Sect. 1). For small and large ships, respectively, 57.3 and $53.6 \%$ of the containers need to be unloaded. The size of the containers varies between 20 and $40 \mathrm{ft}$ containers. On average, there are twice as much 40 as $20 \mathrm{ft}$ containers to be handled. Table 1 summarizes the input data related to ship characteristics. These data will be used in both models.

The dimensions of the ships mooring at Amsterdam Container Terminals do not vary that much. On average, we conclude that 15 bays need to be handled on ships with a small workload and 17 bays on ships with a large workload. Based on some specific ships that regularly moor at the berths of Amsterdam Container Terminals, we have derived representative scenarios how the number of moves usually is divided over the bays. These scenarios are included in Table 2.

\subsection{Quay cranes}

The planning problem of QCs at container terminals consists of two phases (Bierwirth and Meisel 2009). Namely, the Quay Crane Assignment Problem (QCAP) and the Quay Crane Scheduling Problem (QCSP). This latter problem usually consists of two stages, namely the allocation of cranes to sections of the ship and setting the order in which these ship's sections need to be handled (see Steenken et al. 2004). Amsterdam Container Terminals considers these two phases in a sequential way.

In the QCAP, it has to be decided for each arriving ship how many cranes will be assigned to handle all containers. Specific requirements in this problem might be that a set of specific cranes is assigned to a vessel and/or that the number of cranes assigned is unchangeable (Bierwirth and Meisel 2009). We have examined the crane assignments applied in the period under study at Amsterdam Container Terminals (see 
Table 2 Allocation of containers in each bay for ships with a small and large workload

\begin{tabular}{lll}
\hline Bay & \multicolumn{2}{l}{ Percentage of moves in Bay } \\
\cline { 2 - 3 } & $\begin{array}{l}\text { Ship with } \\
\text { a small workload }\end{array}$ & $\begin{array}{l}\text { Ship with } \\
\text { a large workload }\end{array}$ \\
\hline 1 & 3.79 & 3.41 \\
2 & 5.41 & 4.11 \\
3 & 5.64 & 4.86 \\
4 & 6.65 & 5.07 \\
5 & 7.49 & 5.4 \\
6 & 7.99 & 5.99 \\
7 & 8.23 & 6.4 \\
8 & 8.36 & 6.73 \\
9 & 8.36 & 7.19 \\
10 & 8.36 & 7.4 \\
11 & 7.07 & 7.52 \\
12 & 6.89 & 7.52 \\
13 & 6.42 & 7.52 \\
14 & 5.55 & 5.86 \\
15 & 3.79 & 6.19 \\
16 & $\mathrm{n} / \mathrm{a}$ & 5.4 \\
17 & $\mathrm{n} / \mathrm{a}$ & 3.41 \\
\hline & &
\end{tabular}

Sect. 2). Based on these analyses, we conclude that the Amsterdam Container Terminals opt for the option to assign a specific set of cranes. Namely, for ships with a large workload in the indented berth usually six cranes are assigned (Q1-Q6 in Fig.3) and for ships with a small workload three cranes are assigned to handle all tasks (Q1, Q2, and Q4).

Specific data in this context for the marginal berth are taken from Vis and Bakker (2008). At marginal berths ships with a large workload usually are being served by 4 QCs (Q1-Q4 in Fig. 2) and ships with a small workload by 2 QCs (Q1-Q2). We will use these numbers of QCs in our baseline scenario and will vary them in a sensitivity analysis in Sect. 4.

In the QCSP, a set of specific tasks need to be assigned to a set of QCs. Among tasks precedence relations (e.g., first unloading and thereafter loading) might be specified. Furthermore, for QCs spatial constraints might be required to avoid interference between cranes. Bierwirth and Meisel (2009) have formulated a classification to show all options of how the QCSP can be organized at terminals. Each QCSP formulation consists of four values, namely a task attribute, a crane attribute, an interference attribute and a performance measure. Here, we use this classification to describe the specific situation encountered at Amsterdam Container Terminals.

At this terminal a task consists of all unloading and loading operations in a bay. As a result, the allocations of cranes to sections of the ship can be explained as the assignment of the selected cranes to specific bays of a ship (see e.g., Steenken et al. 2004). An important performance measure, also for Amsterdam Container Terminals, 
is an economic utilization of the cranes. A set of tasks will be scheduled per QC and in the resulting schedules it will be indicated that the bays will be handled one by one while working in one direction along the ship. Initial positions of cranes are known. Furthermore, specific safety margins between QCs are respected to avoid interference. Namely, opposite cranes need to have one $40 \mathrm{ft}$ bay in between. Cranes that work next to each other need to have two bays in between. An important performance measure is the finishing time of a $\mathrm{QC}$, which is being recorded by Amsterdam Container Terminals.

The following heuristic is applied to solve the QCSP problem at Amsterdam Container Terminals.

1. Each crane is assigned to a set of bays such that (1) a well-balanced workload over the cranes is obtained; (2) each crane can directly start operations without interfering with opposite and neighboring cranes; (3) each bay is exclusively served by one QC.

2. Each QC unloads bay by bay. In a bay a QC unloads vertically from the inner to the outer site of a bay.

3. To avoid crossing, QCs move from bay to bay in an identical direction along the vessel (i.e., unidirectional schedules, Meisel and Bierwirth 2009). After handling a specific bay, the QC needs to cross to the next bay. Idle times might occur due to the fact that the QC might need to wait to confirm the space constraints and to avoid interference with the cranes.

4. After finishing unloading, a QC starts loading bay by bay while working exactly the other way round.

In Sect. 4 we will discuss the results of the QCSP in more detail. Based on the resulting QC schedules the discharge and load sequence of individual container and the resulting process times can be determined (see e.g., Kim and Park 2004). In the simulation model, we need to include the process times for each single move in a bay. This process time includes the time to pick up a container, transport and deliver the container to its destination and travel to the origin of the next request in the bay. Similar to other papers in this area (see e.g., Kim and Park 2004; Liu et al. 2006), we derive a theoretical distribution to be used in the model. We conclude that we need to distinguish between several distributions to represent the processing times correctly. Namely, cranes at the south side need to transport containers over the water (see Sect. 1) and as a result, processing times are longer. We use the same process time intervals in both distributions. However, the assigned fractions differ over both distributions. As a result, we have the distributions presented in Table 3 summarized as follows:

- Distribution $D 1$ represents processing times for containers being unloaded and loading by cranes closes to the side of the berth where a ship moors, namely at the north side of an indented and the south side of a marginal berth. The weighted average process time per container is $139.5 \mathrm{~s}$.

- Distribution D2 represents processing times for containers being unloaded and loaded by cranes at the south side of an indented berth. The weighted average process time per container is $146.7 \mathrm{~s}$.

For each container in a bay, we will draw a process time from the appropriate distribution. It takes on average $20 \mathrm{~s}$ to cross to next bay. 
Table 3 Empirical distributions $D 1$ and $D 2$ of process times of QCs operating at the north side of an indented berth or the south side of the marginal berth (see Figs. 2 and 3)

\begin{tabular}{l}
$D$ \\
\hline 0.034 \\
0.07
\end{tabular}

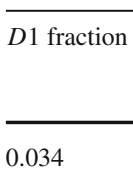$$
0.19
$$

0.1 .3
0.16
0.6

0.177

0.101

0.066

0.054

0.038

0.027

0.024

0.016

0.017

0.013

0.011

0.012

0.008

0.008

0.006

0.005

0.004

0.004

0.004

0.003

0.003

0.003

0.003

0.002

0.001

0.002

0.003

0.002

0.001

0.001

0.002

0.001

0.001

0.001

0.002

0.001
D2 fraction

Interval (s)

Lower bound

50.0

63.7

77.4

91.1

104.8

118.5

132.2

145.9

159.6

173.3

187.0

200.7

214.4

228.1

241.8

255.5

269.2

282.9

296.6

310.3

324.0

337.7

351.4

365.1

378.8

392.5

406.2

419.9

433.6

447.3

461.0

474.7

488.4

502.1

515.8

529.5

543.2

556.9

570.6

584.3
63.7

77.4

91.1

104.8

118.5

132.2

145.9

159.6

173.3

187.0

200.7

214.4

228.1

241.8

255.5

269.2

282.9

296.6

310.3

324.0

337.7

351.4

365.1

378.8

392.5

406.2

419.9

433.6

447.3

461.0

474.7

488.4

502.1

515.8

529.5

543.2

556.9

570.6

584.3

598.0 
Table 4 Distances (in $\mathrm{m}$ ) in the terminal with a marginal berth between stack and ship (and vice versa) (see also Fig. 2)

\begin{tabular}{lrrrrrr}
\hline From/to & S1 & S2 & S3 & S4 & S5 & S6 \\
\hline S1 & & & & & & \\
S2 & 208 & & & & & \\
S3 & 333 & 185 & & & & \\
S4 & 278 & 280 & 437 & & & \\
S5 & 284 & 286 & 291 & 168 & & \\
S6 & 440 & 290 & 295 & 324 & 178 & \\
Q1 & 51 & 150 & 80 & 417 & 271 & 275 \\
Q2 & 223 & 75 & 170 & 325 & 271 & 275 \\
Q3 & 133 & 105 & 260 & 235 & 241 & 365 \\
Q4 & 51 & 199 & 354 & 299 & 305 & 461 \\
\hline
\end{tabular}

In Sect. 3, we will explain how we have modeled the QCSP method in our simulation approach.

\subsection{Straddle carriers}

SCs transport one container at a time. Per QC a pool of $3 \mathrm{SCs}$ is used and as a result an SC only works for a specific QC. We have performed multiple experiments to select one out of the commonly used heuristic rules "nearest vehicle first", "random", "cyclical" and "Largest distance first" (e.g., Egbelu and Tanchoco 1984). The results showed that none of the selection rules outperforms the other ones. The main reason for this is that a container requests an empty SC from a small pool of vehicles. The probability that multiple empty vehicles are available at the same time is small. As a result, most of the time each selection rule will result in the same assignment. Based on these results, we have decided to apply the rule "nearest-vehicle-first" in all experiments.

An SC will be assigned to a container the moment the QC starts unloading the container. An SC will transport the container to its destination via the shortest path. Distances for a marginal berth are given in Table 4. Distances in the terminal with an indented berth are represented in Table 5. An SC needs $22 \mathrm{~s}$ to pick up or put down a container at the marshalling area (Vis and Harika 2004).

\subsection{Stack and storage capacity}

Import containers will be transported to one of the stack blocks. In each block, we distinguish between specific rows for 20 and $40 \mathrm{ft}$ containers. Given the average distribution of 20 and $40 \mathrm{ft}$ containers in the terminal (see Table 1) we assume that in each stack block after each four rows of $40 \mathrm{ft}$ containers, one row is assigned to $20 \mathrm{ft}$ containers. The stacking height equals 3 . Stack capacity in each of the blocks depends on the type of berth and is indicated in Table 6. The total storage capacity is similar for both types of berths. 
Table 5 Distances (in $\mathrm{m}$ ) in the terminal with an indented berth between stack and ship (and vice versa) (see also Fig. 3)

\begin{tabular}{llllllll}
\hline From/to & N1 & N2 & N3 & N4 & S1 & S2 & S3 \\
\hline N1 & $\mathrm{x}$ & & & & & & \\
N2 & $\mathrm{x}$ & $\mathrm{x}$ & & & & & \\
N3 & 299 & 154 & $\mathrm{x}$ & & & & \\
N4 & 381 & 236 & $\mathrm{x}$ & $\mathrm{x}$ & & & \\
S1 & $\mathrm{x}$ & $\mathrm{x}$ & 565 & 562 & $\mathrm{x}$ & & \\
S2 & $\mathrm{x}$ & $\mathrm{x}$ & 420 & 417 & $\mathrm{x}$ & $\mathrm{x}$ & \\
S3 & 513 & 367 & $\mathrm{x}$ & $\mathrm{x}$ & 331 & 186 & $\mathrm{x}$ \\
Q1 & 266 & 121 & 94 & 175 & $\mathrm{x}$ & $\mathrm{x}$ & 328 \\
Q4 & $\mathrm{x}$ & $\mathrm{x}$ & 405 & 402 & 221 & 76 & 171 \\
Q2 & 175 & 60 & 184 & 266 & $\mathrm{x}$ & $\mathrm{x}$ & 419 \\
Q5 & $\mathrm{x}$ & $\mathrm{x}$ & 496 & 493 & 130 & 106 & 262 \\
Q3 & 85 & 151 & 275 & 357 & $\mathrm{x}$ & $\mathrm{x}$ & 510 \\
Q6 & $\mathrm{x}$ & $\mathrm{x}$ & 587 & 584 & 51 & 197 & 352 \\
\hline
\end{tabular}

Table 6 Storage capacity of each of the stack blocks (see Figs. 2 and 3)

\begin{tabular}{lcc}
\hline & 20 feet & 40 feet \\
\hline Indented & \\
N1 & 228 & 444 \\
N2 & 252 & 504 \\
N3 & 168 & 294 \\
N4 & 84 & 189 \\
Indented and marginal & & \\
S1 & 252 & 504 \\
S2 & 252 & 504 \\
S3 & 294 & 567 \\
Marginal & & \\
S4 & 252 & 504 \\
S5 & 252 & 504 \\
S6 & 294 & 567 \\
\hline
\end{tabular}

The time to pick up an export container or to store an import container in the stack including driving times equals on average $58 \mathrm{~s}$ [calculated with operational data obtained from Vis and Harika (2004)]. Import containers will be stored in the stack which is nearest to the marshalling area and that still has an empty spot available. Rows in each stack block will be filled one by one. Export containers will be randomly picked from stacks S3, N3, and N4 (for the indented berth) and S1, S2, and S3 (for the marginal berth). These stack blocks are located closest to the head side of the berth.

We have performed an extensive sensitivity analysis on the values of the input variables in Table 1 to study their impact on the results in relation to various performance measures. We have concluded that the outcomes are insensitive to the values of the 
various input parameters and, therefore, we used the values as described in this section in our simulation model and experiments. The values of the other more design oriented input data as defined here will be used in a baseline scenario.

\section{Simulation model}

We have used Arena 11.0 as simulation software. We have created two simulation models, one for the indented berth and one for the marginal berth. The input data as described in Sect. 2 has been used in the models. As indicated in Fig. 4, we consider both the unloading and loading processes of a ship, which are similar for both types of berths. Different modeling techniques are required for these two processes and therefore, we discuss them subsequently. Based on the description in Sect. 2, Fig. 5 presents a schematic overview of all steps related to the unloading process to be included in the simulation model. This overview can be summarized as follows by using some specific Arena terminology (in italic) to illustrate how the various elements have been modeled.

The model starts with the arrival of a ship. As discussed, a fixed number of containers to be unloaded are created. It is being decided if the container is a $20 \mathrm{or} 40 \mathrm{ft}$ container (see Table 1). A fixed number of QCs handle all containers. Each container is assigned to a specific bay as described in Sect. 2 and indicated in Table 2. Next to that, each QC is assigned to a bay following the guidelines as mentioned in step 1 of the QCSP being performed.

The container in the first bay seizes a QC. When the QC starts unloading this container, an SC (belonging to the pool of vehicles of this QC) is seized to transport the container. The container is delayed by the $\mathrm{QC}$ during a certain process time depending on the physical location of the crane (see Table 3). The QC needs to decide if there is place in the marshalling area and might be delayed if no empty spot is available. The QC will be released by the container the moment the container is available at the marshalling area and can start a new job in the same bay according to the specified order as illustrated in Sect. 2. If both the SC has arrived and the container is available at the marshalling area, than the SC can pick up the container. Before the SC leaves, the nearest available place in one of the stacks is assigned to the container. The SC drives into the stack to place the container on its assigned location which will take a specified handling time (see Sect. 2). The SC will be released by the container and can start a new transportation task for its QC. If all assigned import containers in a specific bay are handled by a QC, then the QC can move to the next bay and start unloading containers in that bay. However, first it needs to be decided if the QC can move to the next bay. If not, the QC waits and regularly it is checked if the QC can move to the next bay. This specific QC waiting time is considered as a special type of idle time and will be recorded separately. If all unloading containers in all assigned bays are handled by a QC, the QC can start with the loading process. Consequently, unloading and loading can take place at the same time in the terminal.

The loading process is depicted in Fig. 6. For each export container, it has to be decided which QC needs to load the container. Furthermore, it has to be decided which size the container has and where it is stored. The container requests an SC that belongs 


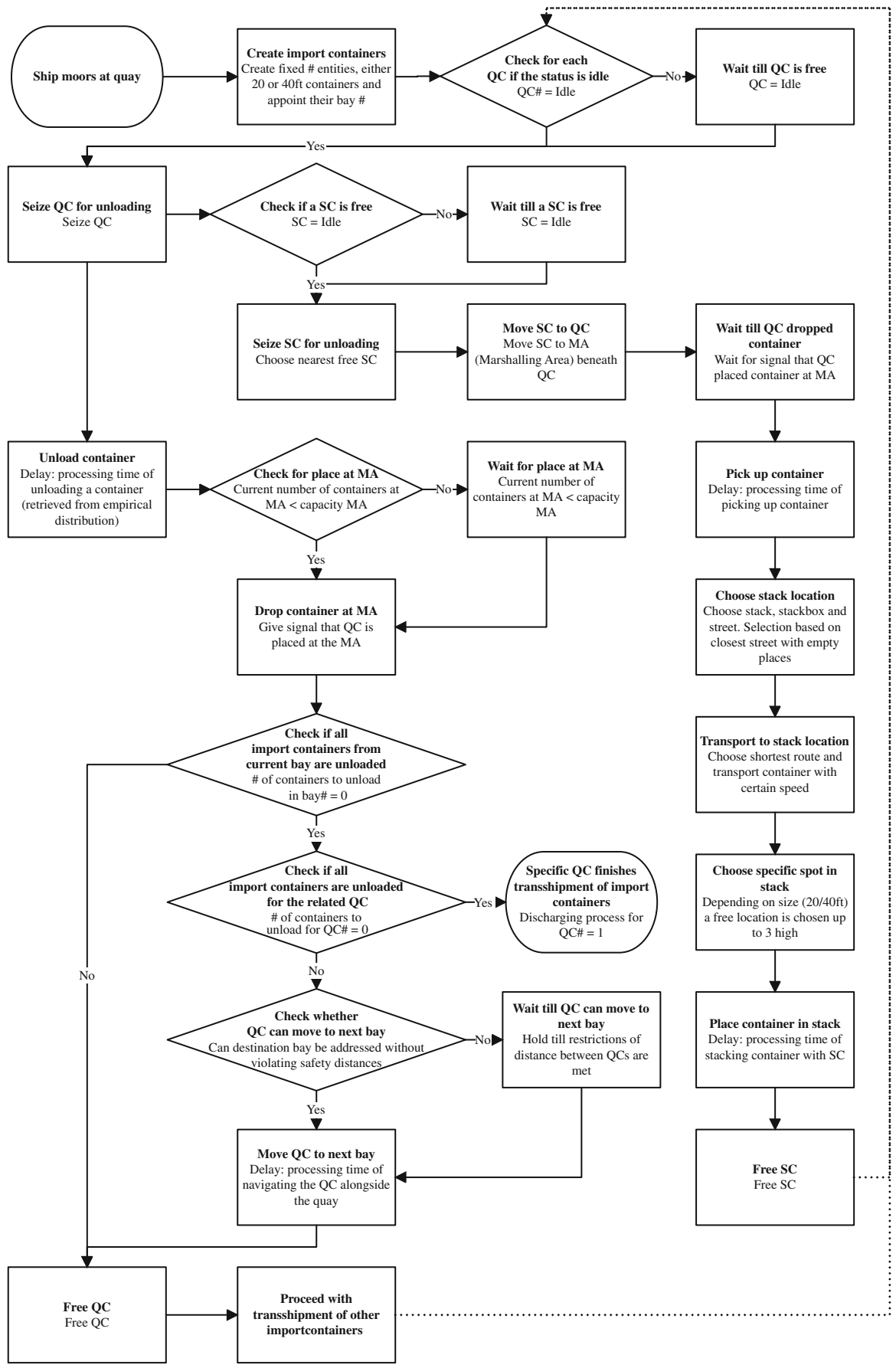

Fig. 5 Overview of model of unloading process 


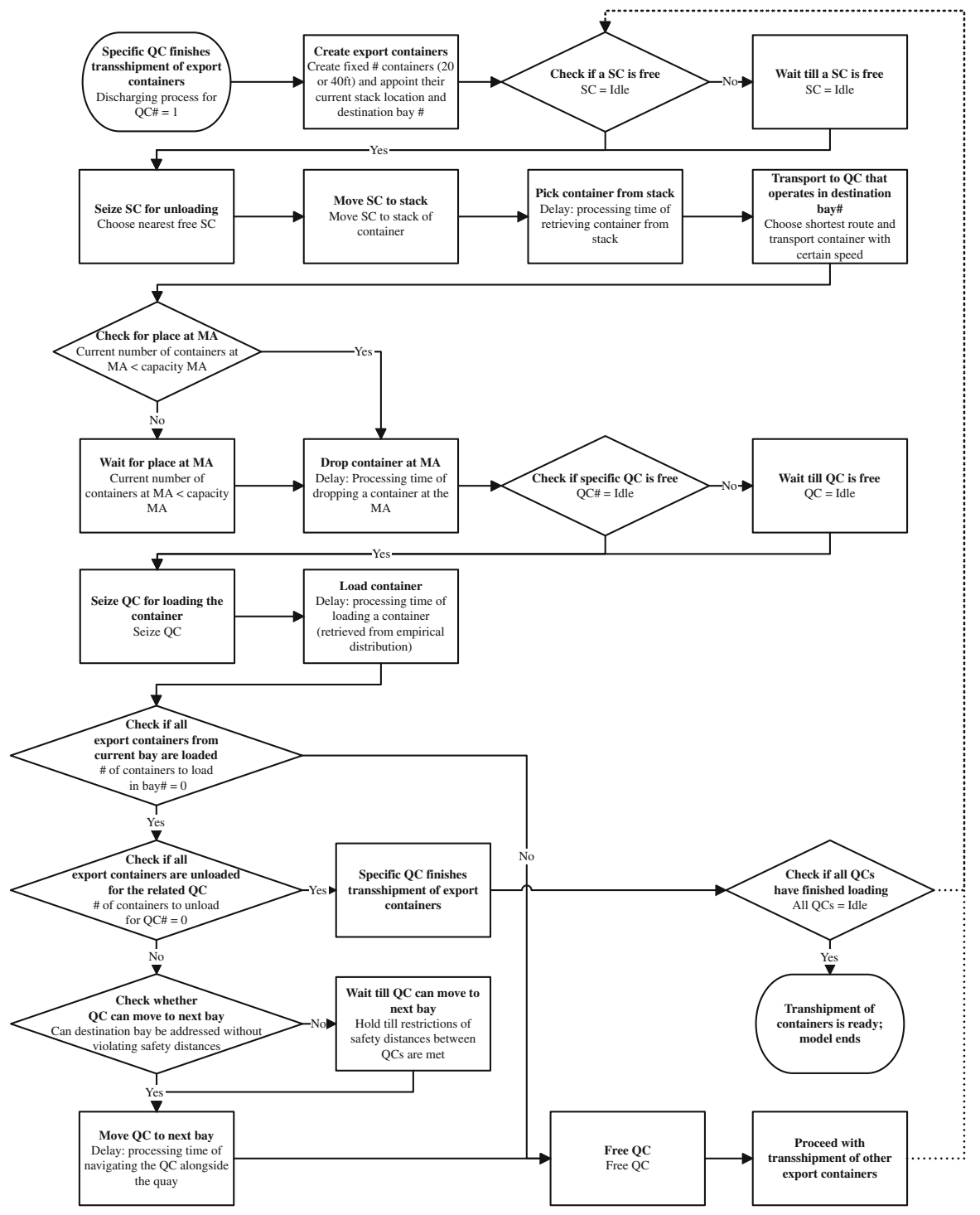

Fig. 6 Overview of model of loading process

to the pool of SCs of its assigned QC. For modeling reasons, we assume that SCs can only be assigned when the specific QC has finished all unloading jobs. Clearly, this will result in some inefficiency in the transition from the unloading to the loading process at the terminal. However, the resulting delays are expected to be around a minute and as a result are relatively small compared to the overall nett processing time to handle a ship. Next to that, we make this assumption for both types of berths and as a result, it does not influence our comparison of both types of berths which is the main goal in this study. It will take the SC some time to pick up the container from the stack 
(see Sect. 2). Thereafter, the container is being transported to the marshalling area. If sufficient place is available at the marshalling area the container will be dropped off, which will take a specified time (see Sect. 2). Otherwise, the SC will be delayed until an empty spot becomes available. After being released by the container, the straddle carrier can start a new transportation request. The QCs have the final task to place the containers onto the ship which will take a certain process time as specified in Table 3. Similar to the unloading process, it needs to be checked before moving to the next bay if this will not result in interference between cranes.

All process times involved in the model are modeled as a delay, except the transport process between the border of the stack and the marshalling area. This quay side transport is modeled with the use of guided vehicles. All distances involved are represented in Tables 4 and 5 .

We assume in both models that all equipment and staff are continuously in operation without break-downs and breaks. As a result, we will use the nett time required to handle a ship as performance measure for both models. Using the data provided in Sect. 2 and the simulation model described here, we have created a baseline scenario for both types of berths. We will discuss in the next section the results for both configurations.

\section{Results}

In this section, we report results of multiple experiments that have been performed. First, we discuss how we validated our model and we introduce relevant performance measures. Second, we present the results of a baseline scenario. Finally, we study the relation between selecting an indented berth and other control issues in the terminal.

\subsection{Model validation}

We have performed two steps to validate our model. First of all, an extensive sensitivity analysis has been performed on all input data to be sure that changes in the selected values did not impact the final results. Next to that, we have compared the outcomes with the actual performance obtained at Amsterdam Container Terminals. It could be concluded that the model reproduces reality.

\subsection{Performance measurement}

Several performance measures can be used to compare the two different terminal configurations. We can distinguish between internal and external performance measures. Liner services are the core clients of a container terminal. Liner services are judging container terminals on different aspects. The most important ones are the location, price, and vessel delay.

Vessel delay is the time that a vessel needs to spend at the container terminal to be unloaded and loaded. The docking time indicates the total time required to moor at the quay, to prepare for and to perform the unloading and loading processes. The time required to moor at an indented berth equals $15 \mathrm{~min}$ and might be somewhat lower for a marginal berth (see Sect. 2). The preparation time can be considered to be equal 
for both types of berths. Therefore, the main performance measure under study here equals the vessel operation time (i.e., actual time required to perform unloading and loading processes). As mentioned in Sect. 3, we exclude break-downs and breaks from our model. As a result, we study the nett vessel operation time.

Important internal performance measures for the terminal are related to the performance of the equipment. SCs and QCs are capital intensive material handling equipment at terminals and so those utilization rates should be maximized. In case of a low utility, it might have been more efficient to deploy fewer vehicles and staff. Utilization rates are interrelated to the QC productivity and the vessel operation time, but we have listed them separately.

Summarizing, we use,

- Nett vessel operation time is the actual time required to perform unloading and loading processes excluding breakdowns, breaks, docking and preparation times

- SC utilization is the SC operation time/SC scheduled time

- QC utilization is the QC working time/ nett vessel operation time.

- QC productivity is the number of moves per hour

The next step is to obtain a reliable comparison between both types of berths we need to simulate multiple ships. Handling a ship can be considered as a terminating system and as a result multiple replications need to be performed for each experiment. By using the formula of Law and Kelton (2000) we have calculated that a replication size of 100 is sufficient for all experiments in this paper. Thus, we randomly generate for each experiment 100 replications and calculate the average value among these 100 replications for each of the selected performance measures.

\subsection{Baseline situation}

For each type of berth, we study the vessel operation times for both a single ship with a small and a large workload. In our simulation study, we simulate one ship at a time as explained as before. As a result, we have first simulated four scenarios representing the baseline situation which was defined in Sects. 2 and 3. For each experiment, we have determined the allocation of QCs to bays based on the specific number of moves in each bay as defined in Table 2 and by applying the heuristic rule as defined in step 1 of the QCSP (see Sect. 2.3). The baseline scenario is summarized in Table 7.

As a result, we perform four simulation experiments separately with a sufficient number of replications for each one. We distinguish between small and large ships being processed at either a marginal or an indented berth. Consequently, we can examine the performance of a single ship in both types of berths and compare the results between both types of berths for both types of ships. Figure 7 presents the average vessel operation times resulting from these experiments.

As shown in Fig. 7, the indented berth outperforms the marginal berth by far. Vessels with a large workload are served within $17.58 \mathrm{~h}$ by $6 \mathrm{QCs}$ at an indented berth. At a marginal berth it takes 4 QCs on average $24.03 \mathrm{~h}$. Vessels with a small workload are served within $13.49 \mathrm{~h} 3 \mathrm{QCs}$ at an indented berth. 2 QCs at a marginal berth use $19.40 \mathrm{~h}$ on average. A $t$-test confirms with $99 \%$ certainty that the indented and marginal berth differ in vessel operation time. Vessel operation times for vessels with a 
Table 7 Four baseline scenarios describing the assignment of specific cranes, the related distribution D1 or D2 for process times of QCs (see Table 3) and the bay assignment resulting from step 1 of the heuristic specified in Sect. 2.3

\begin{tabular}{|c|c|c|c|c|c|}
\hline \multicolumn{3}{|c|}{ Ships with a small workload } & \multicolumn{3}{|c|}{ Ships with a large workload } \\
\hline $\begin{array}{l}\text { QC } \\
\text { assignment }\end{array}$ & $\begin{array}{l}\text { Bay } \\
\text { allocation }\end{array}$ & $\begin{array}{l}\text { Distribution } \\
\text { for process } \\
\text { times }\end{array}$ & $\begin{array}{l}\text { QC } \\
\text { assignment }\end{array}$ & $\begin{array}{l}\text { Bay } \\
\text { allocation }\end{array}$ & $\begin{array}{l}\text { Distribution } \\
\text { for process } \\
\text { times }\end{array}$ \\
\hline \multicolumn{6}{|c|}{ Marginal berth } \\
\hline QC1 & B1-B8 & D1 & QC1 & B1-B5 & D1 \\
\hline \multirow[t]{3}{*}{ QC2 } & B9-B15 & D1 & QC2 & B6-B9 & D1 \\
\hline & & & QC3 & B10-B12 & D1 \\
\hline & & & QC4 & B13-B17 & D1 \\
\hline \multicolumn{6}{|c|}{ Indented berth } \\
\hline $\mathrm{QC1}$ & B1-B6 & D1 & QC1 & B1-B4 & D1 \\
\hline QC4 & B7-B10 & D2 & QC4 & B5-B7 & D2 \\
\hline \multirow[t]{4}{*}{ QC2 } & B11-B15 & D1 & $\mathrm{QC} 2$ & B8-B9 & D1 \\
\hline & & & QC5 & B10-B11 & D2 \\
\hline & & & QC3 & B12-B14 & D1 \\
\hline & & & QC6 & B15-B17 & D2 \\
\hline
\end{tabular}

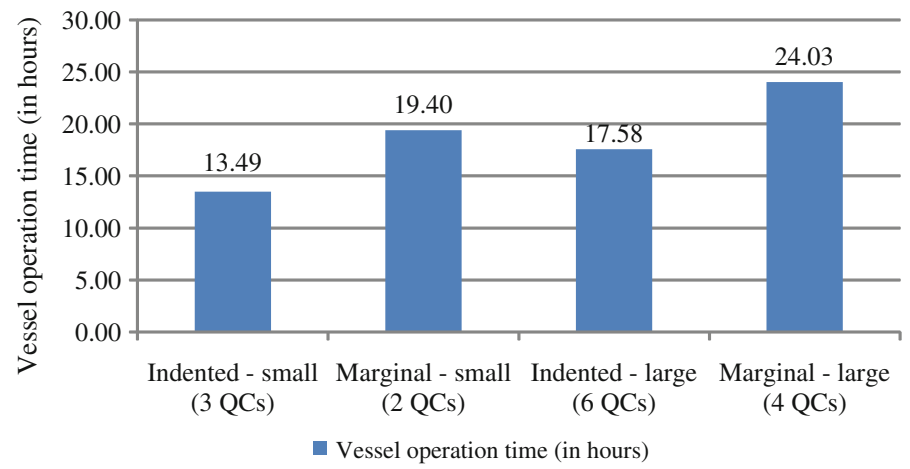

Fig. 7 Indented versus marginal berth in baseline situation

large workload are $27 \%$ lower at an indented berth. Vessels with a small workload can be served $30 \%$ quicker at an indented berth.

At an indented berth more QCs can be deployed since only one bay safety distance needs to be retained. Contrary at a marginal berth safety margins of two bays between neighboring cranes are defined. QC waiting times (as depicted in Table 8 in italic for the baseline scenario) to avoid interference at marginal berths are lower due these less restricting safety margins. However, the additional waiting times at indented berths are totally absorbed in lower vessel operation times. It can be noticed that the utilization of QCs is directly related to the utilization of SCs and at a similar level for both the marginal and indented berth (as depicted in Table 8 in italic for the baseline scenario). 
Table 8 Overview of results for the various performance measures for both types of berths with a varying number of QCs (italic: baseline case)

\begin{tabular}{|c|c|c|c|c|c|}
\hline \#QCs & $\begin{array}{l}\text { QC } \\
\text { productivity }\end{array}$ & $\begin{array}{l}\text { QC } \\
\text { utilization }\end{array}$ & $\begin{array}{l}\text { SC } \\
\text { utilization }^{\mathrm{c}}\end{array}$ & $\begin{array}{l}\text { QC waiting } \\
\text { time for QC } \\
\text { movement to } \\
\text { next bay }\end{array}$ & $\begin{array}{l}\text { Nett vessel } \\
\text { operation } \\
\text { time }^{\mathrm{e}}\end{array}$ \\
\hline
\end{tabular}

Small-indented

324.02

23.34

90.7

71.2

0.017

13.49

4

78.2

61.1

0.882

12.10

$5 \quad 22.43$

85.8

67.5

2.604

9.09

6

20.79

84.9

66.8

5.550

8.35

Small-marginal

$\begin{array}{llllll}2 & 24.25 & 93.7 & 76.9 & 0.000 & 19.40 \\ 3 & 24.15 & 90.8 & 74.7 & 0.033 & 13.38 \\ 4 & 21.87 & 87.4 & 72.0 & 0.046 & 11.52\end{array}$

Large-indented

$3 \quad 24.06$

92.6

74.7

0.017

30.66

$4 \quad 23.88$

85.2

68.4

0.034

$5 \quad 22.77$

83.9

67.7

4.316

21.45

6

22.97

84.3

68.1

3.099

17.58

Large-marginal

$\begin{array}{llllll}2 & 24.31 & 97.5 & 81.8 & 0.000 & 43.22 \\ 3 & 24.37 & 91.3 & 76.9 & 0.033 & 30.72 \\ 4 & 24.02 & 88.7 & 74.4 & 0.033 & 24.03\end{array}$

a The average of 'the number of moves per QC divided by the QC operation time' from all QCs (measured in \# moves per hour)

b The average of 'the operating time divided by the vessel operation time' from all QCs (measured in percentage)

c The average of 'the operating time divided by the scheduled time' from all QCs (measured in percentage)

$\mathrm{d}$ The sum of all waiting times for QC divided by movement to next bay (measured in hours)

e Total operation time (measured in hours)

We will elaborate on these conclusion in Sects. 4.4 and 4.5 by varying the number of equipment assigned to perform operations.

From the results of our baseline scenario, we conclude that more QCs can be deployed at an indented berth and that vessel operation times will increase accordingly despite higher QCs waiting times to avoid QC interferences. Next, we will study the effects of a varying number of QCs on the various performance measures.

\subsection{Varying number of QCs}

Table 8 presents an overview of the results of the baseline situation in italic for both types of berths and the results if we vary the number of QCs. The QC productivity 
varies between 20 and 25 moves per hour in both the marginal and indented berth. In all scenarios, we notice that deploying more QCs results in a decreased QC productivity.

For example, increasing the number of QCs from 3 to 6 for a ship with a large workload at an indented berth results in a decrease of productivity of $4.5 \%$. An important cause of the reduction of QC productivity is the increasing amount of waiting times resulting from QCs that wait to safely navigate to subsequent bays. These waiting times increase with $181 \%$ if we double the number of QCs for a ship with a large workload at the indented berth. However, net vessel operation times decrease with $43 \%$ in this case. We conclude that an increased number of QCs will result in lower vessel operation times although QCs crane drivers will experience higher waiting times to avoid crane interference. Consequently, these significant waiting times seem not impact the vessel operation times as long as they do not concern the bottleneck QC with the highest workload.

Similar figures can be noticed for ships with a small workload at an indented berth. Vessel operation times decrease with $38 \%$ while QC productivity decreases with $13 \%$ when the number of QCs is altered from 3 to 6. Here, QC waiting times even increase with $325 \%$. Ships with a small workload have fewer containers to be handled in a number of bays that is slightly smaller than in ships with a large workload. As a result, QCs will change bays more often.

At marginal berths, we also notice that doubling the number of QCs from 2 to 4 results in a decrease in productivity of QCs and vessel operation times. QC waiting times at marginal berths are much smaller than at an indented berth. For 2 QCs, these waiting times are even zero. This can be explained as follows: workload is equally distributed over both QCs and for a ship with 15 or 17 bays this clearly results in a large distance (measured in bays) directly from the start.

So far, we compared vessel operation times for the case in which we assigned a specific number of QCs to each ship depending on the characteristics of the berth and the QC scheduling approach. As a result, we compared the realistic situation in which a higher number of QCs was assigned to a ship in an indented berth than to a ship in a marginal berth (see Sect.4.3). Comparing scenarios with a similar number of QCs shows that the marginal berth profits from lower waiting times of QCs. Next to that, QCs at the south side of the indented berth experience, on average, higher cycle times due to the transport over water. As a result, marginal berths with a similar amount of QCs deployed will result in somewhat lower vessel operation times. This demonstrates that to profit in an optimal way of the advantages of an indented berth a sufficient number of QCs should be assigned to a ship at both sides of the berth.

Utilization rates of material equipment (see Table 8) will usually be lower when more equipment is assigned to perform operations. Next to that, in our QC scheduling approach we strive for an equal workload distribution which largely defines the utilization rates of both types of material handling equipment. The indented-small scenario with 4 QCs, however, generates somewhat counter-intuitive results from this perspective. Although less QCs are deployed, the utilization rates of both QCs and SCs decrease compared to the scenarios with 5 and 6 QCs. So far, we reported the average utilization over all QCs. The four individual QCs in this scenario have an average utilization rate of, respectively, 99, 78, 71, and 64\%. The average workload of each QC (expressed in a percentage of the total number of moves) is, respectively, 32, 
Table 9 Results for a varying number of SCs per QC at an indented berth

\begin{tabular}{|c|c|c|c|c|c|}
\hline \#SCs & $\begin{array}{l}\text { QC } \\
\text { productivity }\end{array}$ & $\begin{array}{l}\text { QC } \\
\text { utilization }^{\mathrm{b}}\end{array}$ & $\begin{array}{l}\text { SC } \\
\text { utilization }^{\mathrm{c}}\end{array}$ & $\begin{array}{l}\text { QC waiting } \\
\text { time for QC } \\
\text { movement to } \\
\text { next bay }\end{array}$ & $\begin{array}{l}\text { Nett vessel } \\
\text { operation } \\
\text { time }\end{array}$ \\
\hline \multicolumn{6}{|c|}{ Large-indented (6QCs) } \\
\hline 2 & 23.00 & 84.3 & 77.6 & 3.12 & 17.52 \\
\hline 3 & 22.97 & 84.2 & 68.1 & 3.10 & 17.58 \\
\hline 4 & 22.97 & 84.5 & 61.5 & 3.04 & 17.44 \\
\hline \multicolumn{6}{|c|}{ Small-indented (3QCs) } \\
\hline 2 & 24.00 & 90.3 & 83.0 & 0.02 & 13.53 \\
\hline 3 & 24.02 & 90.5 & 71.2 & 0.02 & 13.49 \\
\hline 4 & 24.04 & 90.4 & 63.1 & 0.02 & 13.49 \\
\hline
\end{tabular}

a The average of 'the number of moves per QC divided by the QC operation time' from all QCs (measured in \# moves per hour)

b The average of 'the operating time divided by the vessel operation time' from all QCs (measured in percentage)

$\mathrm{c}$ The average of 'the operating time divided by the scheduled time' from all QCs (measured in percentage)

$\mathrm{d}$ The sum of all waiting times for QC divided by movement to next bay (measured in hours)

e Total operation time (measured in hours)

24,23 , and $21 \%$. These results show that the quay crane scheduling approach results in this specific case in an unequal distribution of workloads over the QCs. We consider the fact that a single bay needs to be handled by a single QC as the main driver for this outcome of the scheduling approach. An interesting point for further research would, therefore, be to study the option of having opposite QCs handling moves from the same bay to check if more equally distributed workloads can be obtained.

In the next section, we will vary the number of SCs used per QC to study the impact on the vessel operation times in a terminal with an indented berth.

\subsection{Number of straddle carriers available}

In the baseline scenario, we used a pool of 3 SCs per QC. In various experiments, we have changed the number of SCs per QC between 2 and 4 to test the impact on vessel operation times. The other input values will be similar to the baseline scenario to allow for studying the impact of this control variable.

From the results in Table 9, we conclude that the vessel operation times are hardly influenced by the number of SCs assigned to each QC. Given the utilization of the SCs, we conclude that the SCs are not functioning as a bottleneck in the terminal under study. The utilization of SCs decreases when more SCs are assigned to a QC. The value of all other relevant performance measures remains the same. Therefore, the number of SCs used in this terminal might be reduced significantly from 3 per QCs to 2 per QC. This equals a reduction of $33 \%$ in the number of vehicles required. The results so far show that it is important to consider the berth configuration selection and equipment decisions in relation to each other. 


\section{Conclusions}

In this paper, we have studied the effect of different types of berth configurations on vessel operation times at container terminals. We have considered both traditional onesided berths and indented berths. At the latter type of berth, quay cranes can handle containers from both sides of the ship. Straddle carriers both execute the transportation process and storage and retrieval processes at the stack. Simulation models for each type of berth have been created in which all relevant logistics processes required for unloading and loading a vessel have been implemented.

We demonstrated that for large ships vessel operation times are, on average, $27 \%$ lower at an indented berth. Small vessels can be served, on average, $30 \%$ quicker at an indented berth. We show that to profit in an optimal way of the double sided handling of a ship a sufficient number of QCs should be assigned to the ship. We conclude that vessel operation times decrease when more QCs are deployed, although QC productivity decreases slightly and QC waiting times increase significantly due to increasing waiting times of QCs to remain the safety distance.

It can be concluded that fewer straddle carriers can be deployed to achieve similar vessel operation times. Other design aspects seem to have less effect on vessel operation times. In further research, it might be interesting to consider several design aspects simultaneously. Next to that, a more sophisticated QC scheduling approach might need to be developed that, for example, allows for splitting the workload of a bay by assigning it to opposite cranes to decrease processing times.

Acknowledgments The authors thank Sandra L. J. van Meersbergen for her contribution in the simulation project that was performed for Amsterdam Container Terminals.

Open Access This article is distributed under the terms of the Creative Commons Attribution Noncommercial License which permits any noncommercial use, distribution, and reproduction in any medium, provided the original author(s) and source are credited.

\section{References}

Bierwirth C, Meisel F (2009) A survey of berth allocation and quay crane scheduling problems in container terminals. Eur J Oper Res. doi:10.1016/j.ejor.2009.05.031

Bish EK, Leong T, Li C, Ng JWC, Simchi-Levi D (2001) Analysis of a new vehicle scheduling and location problem. Naval Res Logist 48:363-385

Egbelu PJ, Tanchoco JMA (1984) Characterization of automatic guided vehicle dispatching rules. Int J Prod Res 22(3):359-374

Imai A, Nishimura E, Papadimitriou S (2001) The dynamic berth allocation problem for a container port. Transport Res Part B 35:401-417

Imai A, Nishimura E, Hattori M, Papadimitriou S (2007) Berth allocation at indented berths for megacontainerships. Eur J Oper Res 179:579-593

Kim KH, Park YM (2004) A crane scheduling method for port container terminals. Eur J Oper Res 156:752768

Kim KH, Park YM, Jin MJ (2007) An optimal lay-out of container yards. OR Spectr 30(4):675-695

Kroon R, Vis IFA (2008) Seriously ceres. In: Ioannou P (eds) Intelligent freight transportation, Chap 6. Taylor and Francis, pp 87-106

Law AM, Kelton WD (2000) Simulation modeling and analysis, 3rd edn. McGraw-Hill, New York

Liu J, Wan YW, Wang L (2006) Quay crane scheduling at container terminals to minimize the maximum relative tardiness of vessel departures. Navel Res Logist 53:60-74 
Meisel F, Bierwirth C (2009) Heuristics for the integration of crane productivity in the berth allocation problem. Transport Res Part E 45:196-209

Nguyen VD, Kim KH (2007) A dispatching method for automated lifting vehicles in automated port container terminals. In: Paper presented at the international conference on intelligent manufacturing and logistics systems (IML 2007), Kitakyushu, Japan, 26-28 February 2007

Stahlbock R, Voss S (2008) Operations research at container terminals: a literature update. OR Spectr 30:1-52

Steenken D, Voss S, Stahlbock R (2004) Container terminal operation and operations research—a classification and literature review. OR Spectr 26:3-49

Vis IFA (2006) A comparative analysis of storage and retrieval equipment at a container terminal. Int J Prod Econ 103:680-693

Vis IFA, Bakker M (2008) Dispatching and layout rules at an automated container terminal. In: Ellis K et al (eds) Progress in material handling research: 2008. Material Handling Institute, Charlotte, North Carolina, pp 685-703

Vis IFA, De Koster R (2003) Transshipment of containers at a container terminal: an overview. Eur J Oper Res 147:1-16

Vis IFA, Harika I (2004) Comparison of vehicle types at an automated container terminal. OR Spectr 26:117-143

Vis IFA, Roodbergen KJ (2009) Scheduling of container storage and retrieval. Oper Res 57:456-467 